\title{
Associations of neighborhood problems and neighborhood social cohesion with mental health and health behaviors: The Multi-Ethnic Study of Atherosclerosis
}

\author{
Sandra Echeverría ${ }^{a, b, *}$, Ana V. Diez-Roux ${ }^{c}$, Steven Shea ${ }^{\mathrm{d}}$, \\ Luisa N. Borrell ${ }^{\mathrm{e}}$, Sharon Jackson ${ }^{\mathrm{f}}$

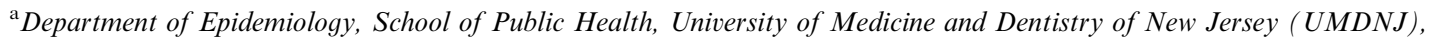 \\ Piscataway, NJ, USA \\ ${ }^{\mathrm{b}}$ Department of Family Medicine, Robert Wood Johnson Medical School, University of Medicine and Dentistry of New Jersey (UMDNJ), \\ Piscataway, NJ, USA \\ ${ }^{\mathrm{c}}$ Department of Epidemiology, University of Michigan School of Public Health, 1214 S. University 2nd Floor, Ann Arbor, \\ MI 48104-2548, USA \\ ${ }^{\mathrm{d}}$ Division of General Medicine, Columbia University College of Physicians and Surgeons, New York, NY, USA \\ ${ }^{\mathrm{e}}$ Department of Epidemiology, Columbia University Mailman School of Public Health, New York, NY, USA \\ ${ }^{\mathrm{f}}$ Division for Heart Disease and Stroke Prevention, National Center for Chronic Disease Prevention and Health Promotion, \\ Centers for Disease Control and Prevention, Atlanta, GA, USA
}

Received 9 March 2007; received in revised form 16 January 2008; accepted 17 January 2008

\begin{abstract}
Few studies have investigated the specific features implicated in neighborhood-health associations. We examined associations between measures of neighborhood problems and neighborhood social cohesion with depression, smoking, drinking, and walking for exercise in the Multi-Ethnic Study of Atherosclerosis (MESA) cohort. Neighborhoods were characterized according to participant self-report and aggregated measures based on other MESA participants. Individuals living in the least problematic neighborhoods were significantly less likely to be depressed, to smoke, or to drink. Less socially cohesive neighborhoods were associated with increased depression, smoking, and not walking for exercise. Results persisted after adjusting for individual-level variables. Each measure appeared to capture distinct features of the neighborhood and associations did not differ by race/ethnicity. Results for neighborhood problems were robust to the use of aggregate measures but results for social cohesion generally were not. Future work should determine the health effect of modifying specific features of the neighborhood context.
\end{abstract}

(C) 2008 Elsevier Ltd. All rights reserved.

Keywords: Neighborhood characteristics; Measurement; Mental health; Health behaviors

\footnotetext{
*Corresponding author. Tel.: + 17322354352 ; fax: +17322354814 .

E-mail address: echevese@umdnj.edu (S. Echeverría).
}

\section{Introduction}

Neighborhood-level deprivation has been consistently associated with various health outcomes (Borrell et al., 2004; Bosma et al., 2001; Diehr 
et al., 1993; Hart et al., 1997; Lee and Cubbin, 2002; O'Campo et al., 1995; Ross, 2000; Silver et al., 2002; Tseng et al., 2001; Centers for Disease Control and Prevention (CDC), 1999; Balfour and Kaplan, 2002). These associations tend to persist after controlling for individual-level measures of socioeconomic position, suggesting that neighborhoodlevel factors are independently related to health. A key feature of these studies has been to characterize neighborhoods according to census-derived socioeconomic indicators. While census-derived indicators have been critical for demonstrating the patterning of disease by levels of socioeconomic deprivation, the specific features of the neighborhood context most relevant for health remain largely unknown. Thus, identifying more specific neighborhood features would strengthen causal inferences regarding neighborhood-health associations and also help identify relevant neighborhood interventions.

Two features of the neighborhood context, namely measures of neighborhood problems and neighborhood social cohesion, have recently gained attention in the literature. Both constructs are related to the concept of social disorganization, generally defined as the inability of communities to realize common values (Sampson and Raudenbush, 1999; Taylor, 1996). Neighborhood problems is a broad term that encompasses both physical or material features of the neighborhood (e.g. abandoned buildings, litter, vandalism) as well as elements of social disorder (e.g. crime, loitering, street conflict, or illicit drug use) (Ross and Mirowsky, 2001). Researchers hypothesize that neighborhood problems may be a source of chronic stress that can contribute to unhealthy coping behaviors such as drinking and smoking, or to poor mental health outcomes (Latkin and Curry, 2003; Roberts et al., 1997; Hill and Angel, 2005). Neighborhood problems may also limit the extent to which persons can be physically active in their area of residence, and thus decrease physical activity levels necessary to maintain health (Centers for Disease Control and Prevention (CDC), 1999). For example, studies have shown that people who fear being robbed, attacked, or physically injured are less likely to report walking for pleasure, exercise, or transportation (Ross, 1993).

The concept of social cohesion (and the related concept of social capital) has gained much prominence in the public health literature in recent years, although the notion of an individual's level of connectedness to his/her community dates as far back as the 19th century (Durkheim, 1997). Sampson and colleagues (Sampson, 2003; Sampson et al., 1997) have provided important theoretical and methodological applications of this concept in recent years. The authors define social cohesion as the degree of connectedness and solidarity that exists among people living in defined geographic boundaries. However, an important distinction in Sampson et al.'s conceptualization of social cohesion is the notion that social ties are not enough to promote collective well-being. What distinguishes 'cohesive' neighborhoods from those with less cohesion, the authors argue, is the collective capacity of residents to translate social ties into specific goals for the common good. In this regard, the authors follow in the line of William Julius Wilson's seminal studies (Wilson, 1987, 1996), indicating that strong local ties among residents of poor neighborhoods did not translate into the strong collective resources needed to effectively manage neighborhood conditions, and that this largely resulted from the absence of viable economic, educational, and political opportunities available to residents of disadvantaged neighborhoods.

Social cohesion is hypothesized to influence health through its role in promoting the adoption of health-related behaviors, increasing access to services and amenities, or through psychosocial processes (Kawachi and Berkman, 2000). For example, neighborhoods with a high degree of social cohesion may promote the rapid diffusion of health-relevant information (especially innovative behaviors) because of the degree of connectedness and trust that exists among neighbors (Rogers, 1983). Also, this degree of connectedness may serve to reinforce health-promoting behaviors such as walking or exercising, or in deterring others (e.g. banning smoking and drinking in public spaces). Individuals in socially cohesive neighborhoods may also be better able to advocate and effect changes in their community directly relevant to health. For example, the placement and maintenance of community health clinics, or resources such as bicycle lanes or gyms promoting exercise, is most likely to occur in neighborhoods that can effectively band together to make these amenities available. Lastly, neighborhood social cohesion may influence psychosocial processes by providing individuals with a source of meaningful connection and mutual respect (Kawachi and Berkman, 2000), and increasing residents' sense of purpose and meaning in life and so contributing to more positive mental health 
outcomes (Silver et al., 2002; Driessen et al., 1998; Weich et al., 2002).

Thus, while measures of neighborhood problems and neighborhood social cohesion have emerged as potentially important features of the neighborhood context (Roberts et al., 1997; Browning and Cagney, 2002; Fisher et al., 2004), little work has been done to empirically determine their association with health outcomes generally, and to test if each of these attributes is independently related to health. In the present study, we examine associations between neighborhood problems and neighborhood social cohesion and depression, smoking, drinking, and walking for exercise. These outcomes were selected because prior theory suggested clear mechanisms through which neighborhood problems and social cohesion could affect their prevalence.

Using cross-sectional data from the Multi-Ethnic Study of Atherosclerosis (MESA), a populationbased cohort composed of White, African-American, Latino and Chinese participants, we tested the following hypotheses: (1) high levels of self-reported neighborhood problems and low levels of neighborhood social cohesion are associated with increased depression, smoking, drinking, and low levels of walking for exercise, after adjusting for individual and neighborhood-level indicators; and (2) neighborhood problems and neighborhood social cohesion capture distinct aspects of the neighborhood context and are each independent predictors of depression and health behaviors. Because the use of self-reported measures of the neighborhood context may introduce biases not typically encountered when using measures derived from other sources (such as a census) we also examined if any observed associations remained robust to alternate ways of measuring neighborhood problems and neighborhood social cohesion. Further, we tested for differences in neighborhood effects by race/ethnicity. We hypothesized that effects might differ due to the strong residential segregation by race/ ethnicity in the United States (US), where neighborhoods with similar measures of problems or cohesion could have very different qualitative characteristics for different race/ethnic groups, and therefore influence health in different ways. In the US context, where race/ethnicity is strongly correlated with socioeconomic factors, different race/ ethnic groups could also have differential resources to buffer the effects of adverse neighborhood environments, providing an additional rationale for possible effect modification.

\section{Methods}

MESA is a prospective cohort study investigating the development of subclinical cardiovascular disease in a multi-ethnic, population-based sample of 6814 men and women. Details of the study design have been published elsewhere (Bild et al., 2002). Briefly, study participants were 45-84 years of age at enrollment, free of clinically apparent cardiovascular disease and recruited from six communities in the US: Baltimore City and Baltimore County, Maryland; Chicago, Illinois; Forsyth County, North Carolina; Los Angeles County, California; New York, New York; and St. Paul, Minnesota. Each site attempted to recruit an equal number of men and women, and included at least two racial/ ethnic groups. Sampling procedures varied across the sites and included either random digit dialing or random selection from available community lists (lists of community residents, enrollees in a health care workers union, or persons enrolled in a national health program for the elderly). To increase the representation of African-American and Latino elders (aged 65 years or older), study participants were asked to refer eligible members to the study, but only 139 of the 1198 elder minority participants were recruited through this method. The final MESA sample was 38\% White, $28 \%$ African-American, 22\% Hispanic/Latino and 12\% Chinese. Data used in these analyses were obtained during the baseline interview conducted from July 2000 to August 2002.

\section{Measures}

Neighborhood characteristics were assessed through questionnaires. Neighborhoods were defined as 'the area around where you live and around your house'. Neighborhood problems were assessed by asking participants to rate several dimensions using a 4-point Likert scale. The neighborhood problem items included excessive noise, heavy traffic or speeding cars, lack of access to adequate food shopping, lack of parks or playgrounds, trash/litter, no sidewalks or poorly maintained sidewalks, and violence. Responses to the items were summed to create a total index score, and then categorized into three groups (tertiles) of roughly equal size. The lower tertile represents the least problematic neighborhoods. The neighborhood social cohesion scale was based on 5-point Likert items asking participants if: their neighborhood is 'close knit', 
neighbors are willing to help each other, neighbors get along, neighbors can be trusted, and neighbors share the same values (Sampson et al., 1997). A total social cohesion score was calculated and divided into roughly equal tertiles, with a higher score representing greater social cohesion. Two week test-retest reliabilities were 0.91 for neighborhood problems and 0.90 for neighborhood social cohesion (Echeverria et al., 2004).

Depression was assessed using the 20-item, Centers for Epidemiologic Studies Depression (CES-D) scale (range of 0-60). This scale has been shown to have high reliability and validity across different populations (Roberts, 1980; Guarnaccia and Worobey, 1989; Jones-Webb and Snowden, 1993; Ying, 1988; Weissman et al., 1977), had a range of $0-50$ in our sample and was log transformed for analyses. Participants were classified as current smokers if they had ever smoked 100 cigarettes or more in their lifetime and reported smoking cigarettes in the past 30 days. Based on prior work (Centers for Disease Control and Prevention (CDC), 2004), individuals consuming five or more drinks on one occasion in the past month were categorized as 'binge' drinkers. Participants were classified as not walking for exercise if they reported that they had not walked for exercise in the past month.

Neighborhood socioeconomic condition was assessed by linking participants to their census tract of residence using their baseline home address. A summary neighborhood score capturing aspects of income/wealth, education, and occupation was used to characterize neighborhood socioeconomic condition (Diez Roux et al., 2001a,b). Neighborhood scores were divided into roughly equal tertiles. Additionally, the length of residency (in years) in the neighborhood was reported by each participant.

Participants' combined family income was classified into five categories: less than $\$ 16,000$; $\$ 16,000-\$ 29,999 ; \quad \$ 30,000-\$ 49,999 ; \quad \$ 50,000-\$ 74$, 999; $\$ 75,000$ or more, and an unknown/not reported category (3\% of sample). Educational attainment was classified as less than high school, completed high school or general equivalency diploma, 1-3 years of college or vocational training, completed 4 years of college, and graduate school training. Race/ethnicity was self-identified and assessed using questions modeled on the Year 2000 Census.

We related each individual's self-report of neighborhood conditions to his or her health outcomes.
There are two important limitations to this approach. One is the possibility for same-source bias stemming from relating self-reported exposure measures to self-reported health outcomes (Macleod et al., 2002). For example, people who are depressed may be more likely to report that their neighborhood has problems or low levels of social cohesion. A second limitation is that self-reports are likely to be a function of both objective reality and individual perceptions. Thus, the use of these measures does not allow separation of whether perception or objective reality (or both) is the health predictor. The validity of individual reports as measures of objective reality could potentially be improved by combining individual reports of several individuals. This is analogous to characterizing a neighborhood by combining information from several raters (Sampson et al., 1997; Raudenbush, 2003). To address these potential limitations, we conducted sensitivity analyses in which a mean score of neighborhood problems and neighborhood social cohesion was constructed for each study participant by summarizing responses from other MESA participants residing in the same neighborhood (i.e. same census tract). Six percent of MESA participants lived in tracts in which no other MESA participant resided, $8 \%$ had 1 other participant living in their census tract, $20 \%$ had $2-5$ people, $14 \%$ had 6-10 people, and 52\% lived in census tracts with 10 or more other MESA participants. Tertiles of neighborhood problems and neighborhood social cohesion were created from these aggregated mean scores and used as predictors in a subsample of participants having at least 2 or more other MESA participants residing in their neighborhood.

Of the 6814 participants in the MESA baseline exam, 6191 participated in the MESA Neighborhood Study and 6188 were geocoded to the census tract level. We excluded individuals who were missing outcome data $(n=78)$ or any single item on neighborhood social cohesion or neighborhood problems $(n=69)$. Individuals who reported taking antidepressant or antipsychotic medications were also excluded $(n=98)$. A total of 5943 participants in 1187 census tracts were available for the main analyses (median of 2.0 participants per census tract, range of 1-245). We did not detect any systematic differences with the small number of participants $(4 \%$ of the Neighborhood Study sample) that were excluded from the final analytic sample. Analyses using aggregated measures of the 
neighborhood characteristics based on 'other' MESA participants were restricted to 5150 participants. The study was approved by the institutional review boards of the participating sites, and all participants gave written informed consent.

\section{Statistical analysis}

The distributions of sociodemographic, individual and neighborhood-level socioeconomic characteristics and health outcomes were examined in the full sample, by race/ethnicity and by tertiles of neighborhood problems and social cohesion. In the absence of a priori hypotheses about particular thresholds, the use of tertiles based on the observed distribution in the data provides the most efficient and informative analysis. Associations of the neighborhood attributes with the outcomes were examined using linear regression (for log transformed CESD score) or binomial regression (Spiegelman and Hertzmark, 2005; Wacholder, 1986; Zou, 2004) to calculate prevalence ratios (PR) for smoking, binge drinking, and walking for exercise. Separate models were fitted for each outcome and for neighborhood problems and neighborhood social cohesion. Model 1 was unadjusted for any covariates; Model 2 adjusted for age and sex; Model 3 added personal income, education, and race/ ethnicity to Model 2; Model 4 added both problems and cohesion (using individual-level self-reported measures) to Model 3; and Model 5 added the socioeconomic neighborhood index and length of residence in the neighborhood to Model 4. Neighborhood socioeconomic condition was included in Model 5 in order to determine if associations were independent of neighborhood-level socioeconomic conditions and factors correlated with this measure. Tests for trend across the neighborhood measures were conducted by entering the neighborhood attributes as ordinal variables in regression models. Interactions between tertiles of neighborhood characteristics and race/ethnicity and gender were tested by entering appropriate cross-product terms in the models. Associations were unchanged when adjusting for study site, so study site was not included in the final models. Models 1-4 were repeated using the aggregated measures of neighborhood problems and neighborhood social cohesion (as reported by other MESA participants) and compared to individual-level self-reported measures. The Generalized Estimating Equations (GEE) approach was used to account for potential correlations in study outcomes between participants residing in the same neighborhoods. All analyses were performed using SAS 9.0. Reported $p$-values are two-tailed and all confidence intervals are $95 \%$.

\section{Results}

White participants had higher levels of income and education and tended to live in more advantaged neighborhoods than all other racial/ethnic groups (Table 1). Mean scores for neighborhood problems were slightly higher for African-Americans and Latinos than for Whites, and social cohesion scores were slightly lower for AfricanAmericans and Latinos compared to Whites. Chinese participants reported lower levels of neighborhood problems than all other racial/ethnic groups. Latinos generally had the poorest health outcomes (higher levels of depression, drinking and not walking for exercise), while the proportion of smokers was highest among African-Americans.

In bivariate analyses, higher levels of neighborhood problems were associated with higher mean CES-D scores and higher prevalence of smoking and alcohol drinking (tests for trend $p<0.001$ ), but neighborhood problems were not associated with walking $(p=0.31)$ (Table 2). Higher levels of social cohesion were associated with lower mean CES-D scores, lower prevalence of smoking, and higher prevalence of walking for exercise (tests for trend $p<0.001)$. Social cohesion was not associated with alcohol drinking $(p=0.57)$.

These patterns generally remained after adjustment for covariates. Individuals living in neighborhoods with the least problems were significantly less likely to report depressive symptoms (mean difference in $\log$ CES-D $=-0.36$, CI $=-0.42,-0.30$ ) than those living in the most problematic neighborhoods after adjustment for individual-level variables (Model 3, Table 3). A mean difference of -0.36 in the $\log$ of CES-D is equivalent to a $30 \%$ reduction in the original CES-D scale. Participants living in the least problematic neighborhoods were also almost $20 \%$ less likely to smoke currently (PR = $0.81, \mathrm{CI}=0.68,0.96)$ or to consume 5 or more drinks per occasion $(\mathrm{PR}=0.81, \mathrm{CI}=0.65,1.00)$ than those living in the most problematic neighborhoods (Model 3, Table 3). Neighborhood problems were not associated with walking before or after adjusting for covariates. Associations of neighborhood problems with depression, smoking or drinking were largely unchanged when social cohesion 
Table 1

Sample characteristics at baseline, Multi-Ethnic Study of Atherosclerosis (MESA), 2000-2002

\begin{tabular}{|c|c|c|c|c|c|}
\hline Sample characteristics & $\begin{array}{l}\text { Total sample } \\
N=5943\end{array}$ & $\begin{array}{l}\text { Whites } \\
N=2327\end{array}$ & $\begin{array}{l}\text { African-Americans } \\
N=1610\end{array}$ & $\begin{array}{l}\text { Latinos } \\
N=1286\end{array}$ & $\begin{array}{l}\text { Chinese } \\
N=720\end{array}$ \\
\hline \multicolumn{6}{|l|}{ Demographic characteristics } \\
\hline Mean age at baseline & 61.8 & 62.3 & 61.8 & 61.7 & 61.2 \\
\hline Participants 65 years of age or older $(\%)$ & 42.5 & 44.0 & 42.0 & 40.0 & 42.0 \\
\hline \multicolumn{6}{|l|}{ Gender (\%) } \\
\hline Male & 48.0 & 49.0 & 45.6 & 48.4 & 49.3 \\
\hline Female & 52.0 & 51.0 & 54.4 & 51.6 & 50.7 \\
\hline \multicolumn{6}{|l|}{ Education $(\%)$} \\
\hline Less than high school & 16.7 & 4.4 & 11.4 & 42.9 & 21.8 \\
\hline Completed high school & 17.9 & 16.6 & 18.5 & 20.8 & 16.1 \\
\hline Some college & 28.3 & 27.2 & 35.3 & 25.9 & 21.0 \\
\hline BA degree & 18.3 & 23.6 & 18.2 & 5.9 & 23.8 \\
\hline Graduate training & 18.7 & 28.3 & 16.7 & 4.6 & 17.4 \\
\hline \multicolumn{6}{|l|}{ Annual family income $(\%)$} \\
\hline Less than $\$ 16,000$ & 17.3 & 6.6 & 15.0 & 30.2 & 33.2 \\
\hline$\$ 16,000-\$ 29,999$ & 18.1 & 12.1 & 19.0 & 27.3 & 19.2 \\
\hline$\$ 30,000-\$ 49,999$ & 23.4 & 22.7 & 26.4 & 24.2 & 17.8 \\
\hline$\$ 50,000-\$ 74,999$ & 17.4 & 20.3 & 21.3 & 10.5 & 11.9 \\
\hline$\$ 75,000$ or more & 23.9 & 38.2 & 18.3 & 7.8 & 18.1 \\
\hline Unknown & 3.3 & 2.2 & 7.4 & 2.0 & 0.7 \\
\hline \multicolumn{6}{|l|}{ Neighborhood characteristics } \\
\hline $\begin{array}{l}\text { Mean number of years living in neighborhood } \\
\text { (SD) }\end{array}$ & $18.9(14.2)$ & $20.7(15.0)$ & $19.8(13.7)$ & $18.8(14.1)$ & $11.1(9.9)$ \\
\hline Median neighborhood socioeconomic score & -0.73 & 2.44 & -2.42 & -3.32 & 1.01 \\
\hline Mean number of neighborhood problems (SD) & $10.4(3.3)$ & $10.4(3.0)$ & $10.9(3.6)$ & $10.6(3.6)$ & $8.8(2.9)$ \\
\hline Mean social cohesion scale (SD) & $17.6(2.9)$ & $18.0(2.8)$ & $17.7(3.0)$ & $16.9(2.9)$ & $17.0(2.4)$ \\
\hline Cronbach's alpha for social cohesion scale & 0.70 & 0.71 & 0.74 & 0.66 & 0.60 \\
\hline $\begin{array}{l}\text { Correlation between neighborhood problems } \\
\text { and social cohesion scale }\end{array}$ & -0.30 & -0.31 & -0.37 & -0.34 & -0.18 \\
\hline \multicolumn{6}{|l|}{ Health Outcomes at baseline } \\
\hline Mean CES-D score $(\mathrm{SD})^{\mathrm{a}}$ & $7.3(7.4)$ & $6.8(6.8)$ & $7.1(7.0)$ & $9.3(8.8)$ & $6.2(6.5)$ \\
\hline Percent with depressive symptoms ${ }^{\text {b }}$ & 12.0 & 9.4 & 10.9 & 20.1 & 8.1 \\
\hline Percent current smoker & 12.6 & 10.8 & 17.7 & 13.2 & 5.6 \\
\hline $\begin{array}{l}\text { Percent having } 5 \text { or more drinks/occasion (past } \\
\text { month) }\end{array}$ & 8.2 & 9.7 & 6.3 & 11.7 & 1.4 \\
\hline Percent not walking for exercise & 34.9 & 27.7 & 37.4 & 41.5 & 40.4 \\
\hline
\end{tabular}

${ }^{\mathrm{a}}$ Increasing CES-D score indicates increasing symptoms of depression.

${ }^{\mathrm{b}}$ Defined as individuals with scores of 16 and above.

(Model 4, Table 3) or neighborhood socioeconomic conditions (Model 5, Table 3) were added to the models. There was no evidence of substantive differences in effects across race/ethnic groups for all health outcomes, except depression. The overall $p$-value for interaction between neighborhood problems and race/ethnicity for the depression outcome was 0.004 . Specifically, the associations of neighborhood problems with CES-D were stronger in Latino and Chinese participants than in the other groups: mean difference in $\log$ CES-D comparing least problematic to most problematic neighborhoods was $-0.48 \quad(-0.60,-0.35)$ for Latinos; -0.57 $(-0.75,-0.39)$ for those of Chinese descent; -0.32 $(-0.44,0.21)$ for African-Americans; and -0.26 $(-0.35,-0.17)$ for Whites.

Individuals living in the least socially cohesive neighborhoods had higher CES-D scores than those living in the more socially cohesive neighborhoods (mean difference in $\log \mathrm{CES}-\mathrm{D}=0.21, \mathrm{CI}=0.15$, 0.27 ) after adjustment for individual-level covariates (Model 3, Table 4). They were also more likely to smoke (PR for $1.24, \mathrm{CI}=1.06,1.45$ ) and to not walk for exercise (PR 1.15, CI $=1.05,1.26$ ). 
Table 2

Mean level of depression and prevalence of current smoking, alcohol drinking, and not walking for exercise, by tertiles of neighborhood characteristics

\begin{tabular}{lcccc}
\hline $\begin{array}{l}\text { Neighborhood } \\
\text { characteristic }\end{array}$ & $\begin{array}{l}\text { Depression (CES-D } \\
\text { score) }\end{array}$ & $\begin{array}{l}\text { Current } \\
\text { smoking }\end{array}$ & $\begin{array}{l}\text { Alcohol drinking (5 or more drinks/ } \\
\text { occasion) }\end{array}$ & $\begin{array}{l}\text { Not walking for } \\
\text { exercise }\end{array}$ \\
\hline $\begin{array}{l}\text { Neighborhood problems } \\
1 \text { (Low) }\end{array}$ & $6.0(\mathrm{SD}=6.5)$ & 10.2 & 6.2 & 35.6 \\
2 & $7.0(\mathrm{SD}=7.0)$ & 12.1 & 9.3 & 34.8 \\
3 (High) & $8.9(8.0)$ & 15.1 & 9.3 & 34.2 \\
$P$ for trend & $<0.001$ & $<0.001$ & $<0.001$ & 0.31 \\
Neighborhood social cohesion & & & 39.5 \\
1 (Low) & $8.6(8.1)$ & 14.7 & 8.2 & 34.2 \\
2 & $7.1(7.0)$ & 12.0 & 8.8 & 31.2 \\
3 (High) & $6.3(6.7)$ & 11.0 & 7.7 & $<0.001$ \\
$P$ for trend & $<0.001$ & $<0.001$ & 0.57 & \\
\hline
\end{tabular}

\section{Table 3}

Crude and adjusted mean differences in log CES-D scores and prevalence ratios of current smoking, drinking, and walking for exercise by tertiles of neighborhood problems, $\mathrm{MESA}^{\mathrm{a}}$

\begin{tabular}{|c|c|c|c|c|c|}
\hline $\begin{array}{l}\text { Neighborhood } \\
\text { characteristic }\end{array}$ & Model 1 (crude) & Model 2 & Model 3 & Model 4 & Model 5 \\
\hline Neighborhood problems & \multicolumn{5}{|c|}{ Mean differences (95\% CI): CES-D score } \\
\hline 1 (Low) & $\begin{array}{l}-0.39 \\
(-0.45,-0.34)\end{array}$ & $\begin{array}{l}-0.38 \\
(-0.44,-0.33)\end{array}$ & $\begin{array}{l}-0.36 \\
(-0.42,-0.30)\end{array}$ & $\begin{array}{l}-0.33 \\
(-0.39,-0.27)\end{array}$ & $\begin{array}{l}-0.34 \\
(-0.40,-0.28)\end{array}$ \\
\hline 2 & $\begin{array}{l}-0.22 \\
(-0.28,-0.17)\end{array}$ & $\begin{array}{l}-0.21 \\
(-0.27,-0.16)\end{array}$ & $\begin{array}{l}-0.20 \\
(-0.26,-0.14)\end{array}$ & $\begin{array}{l}-0.18 \\
(-0.24,-0.12)\end{array}$ & $\begin{array}{l}-0.19 \\
(-0.25,-0.13)\end{array}$ \\
\hline 3 (High) & Ref. & Ref. & Ref. & Ref. & Ref. \\
\hline Neighborhood problems & \multicolumn{5}{|c|}{ Prevalence ratios $(95 \%$ CI): current smoking } \\
\hline 1 (Low) & $0.72(0.60,0.86)$ & $0.74(0.62,0.88)$ & $0.81(0.68,0.96)$ & $0.84(0.70,1.00)$ & $0.85(0.71,1.0)$ \\
\hline 2 & $0.83(0.69,0.99)$ & $0.83(0.70,0.99)$ & $0.88(0.74,1.04)$ & $0.90(0.76,1.10)$ & $0.90(0.76,1.10)$ \\
\hline 3 (High) & Ref. & Ref. & Ref. & Ref. & Ref. \\
\hline Neighborhood problems & \multicolumn{5}{|c|}{ Drinking ( 5 or more drinks in one occasion) } \\
\hline 1 (Low) & $0.78(0.62,0.98)$ & $0.77(0.62,0.97)$ & $0.81(0.65,1.00)$ & $0.81(0.66,1.00)$ & $0.83(0.67,1.02)$ \\
\hline 2 & $1.1(0.87,1.34)$ & $1.04(0.85,1.28)$ & $1.02(0.83,1.24)$ & $1.02(0.83,1.24)$ & $1.03(0.84,1.26)$ \\
\hline 3 (High) & Ref. & Ref. & Ref. & Ref. & Ref. \\
\hline Neighborhood problems & \multicolumn{5}{|c|}{ Not walking for exercise } \\
\hline 1 (Low) & $1.04(0.94,1.15)$ & $1.05(0.95,1.15)$ & $1.01(0.92,1.10)$ & $1.05(0.95,1.16)$ & $1.08(0.97,1.20)$ \\
\hline 2 & $1.02(0.93,1.13)$ & $1.03(0.93,1.13)$ & $1.04(0.95,1.14)$ & $1.06(0.97,1.17)$ & $1.07(0.97,1.19)$ \\
\hline 3 (High) & Ref. & Ref. & Ref. & Ref. & Ref. \\
\hline
\end{tabular}

${ }^{a}$ Model 1: crude; Model 2: adjusted for age and sex; Model 3: adjusted for age, sex, income $(<\$ 16,000, \$ 16,000-\$ 29,999$, $\$ 30,000-\$ 49,999, \$ 50,000-\$ 74,999$ or $\$ 75,000+$ ), education (less than high school (HS), completed HS, some college, BA degree, graduate school), and race/ethnicity; Model 4: adjusted for age, sex, income, education, race/ethnicity and neighborhood problems and neighborhood social cohesion; Model 5: adjusted for age, sex, income, education, race/ethnicity, neighborhood problems and neighborhood social cohesion, length of residency in neighborhood and neighborhood-level socioeconomic condition. (Summary index composed of the following items: log of the median household income; log of the median value of owner-occupied housing units; proportion of households receiving interest, dividend, or net rental income; proportion of adults $\geqslant 25$ years of age with a high-school diploma; proportion of adults $\geqslant 25$ years of age who had completed college; and proportion of people employed in executive, managerial, or professional specialty occupations. The index was constructed by summing the $Z$ scores for each of the neighborhood-level variables with $Z$ scores constructed using the mean and SD for all US census tracts in the Year 2000 Census. The total score for the census tracts represented in the sample ranged from -11.1 to 13.7 , with increasing scores indicating increasing neighborhood socioeconomic advantage). 
Table 4

Crude and adjusted mean differences in log CES-D scores and prevalence ratios of current smoking, drinking, and walking for exercise by tertiles of neighborhood social cohesion, $\mathrm{MESA}^{\mathrm{a}}$

\begin{tabular}{|c|c|c|c|c|c|}
\hline Neighborhood characteristic & Model 1 (crude) & Model 2 & Model 3 & Model 4 & Model 5 \\
\hline Neighborhood social cohesion & \multicolumn{5}{|c|}{ Mean differences $(95 \%$ CI): CES-D score } \\
\hline 1 (Low) & $0.27(0.21,0.33)$ & $0.27(0.21,0.33)$ & $0.21(0.15,0.27)$ & $0.13(0.07,0.19)$ & $0.13(0.07,0.19)$ \\
\hline 2 & $0.11(0.05,0.17)$ & $0.11(0.05,0.17)$ & $0.08(0.02,0.14)$ & $0.05(-0.01,0.11)$ & $0.05(-0.01,0.11)$ \\
\hline 3 (High) & Ref. & Ref. & Ref. & Ref. & Ref. \\
\hline Neighborhood social cohesion & \multicolumn{5}{|c|}{ Prevalence ratios $(95 \%$ CI): current smoking } \\
\hline 1 (Low) & $1.34(1.13,1.58)$ & $1.32(1.13,1.54)$ & $1.24(1.06,1.45)$ & $1.18(1.01,1.39)$ & $1.17(0.99,1.37)$ \\
\hline 2 & $1.09(0.91,1.30)$ & $1.07(0.91,1.27)$ & $1.10(0.93,1.31)$ & $1.08(0.91,1.28)$ & $1.08(0.91,1.28)$ \\
\hline 3 (High) & Ref. & Ref. & Ref. & Ref. & Ref. \\
\hline Neighborhood social cohesion & \multicolumn{5}{|c|}{ Drinking ( 5 or more drinks in one occasion) } \\
\hline 1 (Low) & $1.0(0.77,1.29)$ & $1.02(0.81,1.27)$ & $1.04(0.83,1.29)$ & $0.99(0.80,1.23)$ & $1.0(0.81,1.24)$ \\
\hline 2 & $1.1(0.83,1.44)$ & $1.08(0.84,1.37)$ & $1.15(0.92,1.43)$ & $1.11(0.90,1.39)$ & $1.1(0.90,1.39)$ \\
\hline 3 (High) & Ref. & Ref. & Ref. & Ref. & Ref. \\
\hline Neighborhood social cohesion & \multicolumn{5}{|c|}{ Not walking for exercise } \\
\hline 1 (Low) & $1.28(1.17,1.39)$ & $1.27(1.17,1.39)$ & $1.15(1.05,1.26)$ & $1.17(1.05,1.29)$ & $1.17(1.05,1.29)$ \\
\hline 2 & $1.10(1.01,1.20)$ & $1.10(1.0,1.26)$ & $1.04(0.95,1.14)$ & $1.05(0.96,1.15)$ & $1.05(0.96,1.15)$ \\
\hline 3 (High) & Ref. & Ref. & Ref. & Ref. & Ref. \\
\hline
\end{tabular}

${ }^{a}$ Model 1: crude; Model 2: adjusted for age and sex; Model 3: adjusted for age, sex, income $(<\$ 16,000, \$ 16,000-\$ 29,999$, $\$ 30,000-\$ 49,999, \$ 50,000-\$ 74,999$ or $\$ 75,000+$ ), education (less than high school (HS), completed HS, some college, BA degree, graduate school), and race/ethnicity; Model 4: adjusted for age, sex, income, education, race/ethnicity and neighborhood problems and neighborhood social cohesion; Model 5: adjusted for age, sex, income, education, race/ethnicity, neighborhood problems and neighborhood social cohesion, length of residency in neighborhood and neighborhood-level socioeconomic condition. (Summary index composed of the following items: log of the median household income; log of the median value of owner-occupied housing units; proportion of households receiving interest, dividend, or net rental income; proportion of adults $\geqslant 25$ years of age with a HS diploma; proportion of adults $\geqslant 25$ years of age who had completed college; and proportion of people employed in executive, managerial, or professional specialty occupations. The index was constructed by summing the $Z$ scores for each of the neighborhood-level variables with $Z$ scores constructed using the mean and SD for all US census tracts in the Year 2000 Census. The total score for the census tracts represented in the sample ranged from -11.1 to 13.7 , with increasing scores indicating increasing neighborhood socioeconomic advantage).

Neighborhood social cohesion was not associated with drinking before or after adjusting for covariates. Associations of social cohesion with CES-D, smoking, and walking were reduced in magnitude but generally remained statistically significant after adjusting for neighborhood problems and neighborhood socioeconomic characteristic (Models 4 and 5, Table 4). The only significant interaction between neighborhood social cohesion and race/ethnicity was observed for the walking outcome $(p=0.03)$ Specifically, no associations were observed in Latinos ( $\mathrm{PR}=0.97, \mathrm{CI}=0.81,1.16)$ when comparing those living in low to high social cohesion neighborhoods, and similar associations were observed in the other race/ethnic groups $(\mathrm{PR}=1.26$, $\mathrm{CI}=1.11,1.50$ for African-Americans; $\mathrm{PR}=1.19$, $\mathrm{CI}=0.97, \quad 1.47$ for Chinese individuals; and $\mathrm{PR}=1.21, \mathrm{CI}=1.04,1.41$ for Whites).

Models using aggregate measures of neighborhood problems based on other MESA participants generally indicated similar patterns to those found in models using individuals' self-report (although associations with depression were slightly weaker and associations with smoking and drinking were slightly stronger when aggregate measures were used (compare Table 5 to Model 3 in Table 3). In the case of social cohesion, associations with depression disappeared, associations of low social cohesion with increased smoking and drinking were marginally significant, and low social cohesion was associated with lower rather than higher prevalence of not walking for exercise when aggregate measures were used (compare Table 5 to Model 3 in Table 4).

\section{Discussion}

The MESA cohort allowed us to examine the association of neighborhood problems and neighborhood social cohesion with depression and health behaviors in a large and ethnically diverse 
Table 5

Mean difference in log CESD score and prevalence ratios (PR) of current smoking, alcohol drinking, not walking for exercise, adjusted for age, sex, income, education, and race/ethnicity, by tertiles of aggregate measures of neighborhood problems and neighborhood social cohesion $^{\mathrm{a}}$

\begin{tabular}{|c|c|c|c|c|c|c|c|c|}
\hline \multirow[t]{2}{*}{ Neighborhood characteristic } & \multicolumn{2}{|l|}{ CES-D score } & \multicolumn{2}{|c|}{$\begin{array}{l}\text { Current } \\
\text { smoking }\end{array}$} & \multicolumn{2}{|c|}{$\begin{array}{l}\text { Alcohol drinking ( } 5 \text { or more } \\
\text { drinks) }\end{array}$} & \multicolumn{2}{|c|}{$\begin{array}{l}\text { Not walking for } \\
\text { exercise }\end{array}$} \\
\hline & Mean difference & $95 \% \mathrm{CI}$ & PR & $95 \% \mathrm{CI}$ & PR & $95 \% \mathrm{CI}$ & PR & $95 \% \mathrm{CI}$ \\
\hline \multicolumn{9}{|l|}{ Neighborhood problems } \\
\hline 1 (Low) & -0.21 & $-0.29,-0.13$ & 0.69 & $0.56,0.85$ & 0.63 & $0.49,0.82$ & 1.06 & $0.96,1.16$ \\
\hline 2 & -0.05 & $-0.12,0.02$ & 0.97 & $0.81,1.15$ & 0.88 & $0.72,1.08$ & 0.99 & $0.90,1.09$ \\
\hline 3 (High) & Ref. & & Ref. & & Ref. & & Ref. & \\
\hline \multicolumn{9}{|l|}{ Neighborhood social cohesion } \\
\hline 1 (Low) & 0.05 & $-0.03,0.13$ & 1.18 & $0.96,1.44$ & 1.26 & $0.96,1.66$ & 0.90 & $0.81,1.00$ \\
\hline 2 & 0.01 & $-0.05,0.08$ & 1.09 & $0.90,1.32$ & 1.35 & $1.07,1.69$ & 1.0 & $0.92,1.10$ \\
\hline 3 (High) & Ref. & & Ref. & & Ref. & & Ref. & \\
\hline
\end{tabular}

${ }^{a}$ CES-D scores were log transformed. Analyses restricted to two or more 'other' MESA participants residing in the same tract $(N=5150)$. Outcomes adjusted for age, sex, income $(<\$ 16,000, \$ 16,000-\$ 29,999, \$ 30,000-\$ 49,999, \$ 50,000-\$ 74,999$ or $\$ 75,000+)$, education (less than high school (HS), completed HS, some college, BA degree, graduate school), and race/ethnicity.

population-based sample. Our findings suggest that neighborhood problems are positively associated with depression, current smoking and alcohol drinking whether individual or aggregate measures are used. These associations were statistically independent of individual-level socioeconomic factors, neighborhood socioeconomic characteristics and race/ethnicity. Participants who reported living in the least socially cohesive neighborhoods had significantly higher CES-D scores and were more likely to smoke and not walk for exercise. However, these associations became weaker and sometimes changed direction when measures based on the report of other residents (rather than self-reports) were used. With the possible exception of depression among Latino and Chinese participants, there was no evidence that these associations differed substantively by race/ethnicity, and each of the specific neighborhood features examined appeared to capture distinct neighborhood attributes.

Our study supports previous findings suggesting an association between neighborhood problems and poor mental health (Latkin and Curry, 2003; Aneshensel and Sucoff, 1996; Macintyre and Ellaway, 2000; Ross et al., 2000; Sooman and Macintyre, 1995; Steptoe and Feldman, 2001; van der Linden et al., 2003). Studies relating neighborhood problems to health behaviors are less common. One US study has suggested that problematic neighborhoods can lead people to engage in healthdamaging behaviors (such as heavy drinking) as a means of palliative escape (Hill and Angel, 2005).
A British study (Steptoe and Feldman, 2001) has reported no association between a 10-item index of neighborhood problems and smoking, heavy drinking, physical inactivity and lack of consumption of fruits and vegetables, but the low response rate of the study $(24 \%)$ and limited variability in the neighborhood measures could have contributed to these results. Our test of the consistency of results using individual or aggregate-level measures of neighborhood problems strengthens the inference that the associations we observed did not result from reporting bias.

Walking for exercise was the only outcome not associated with neighborhood problems in our sample. Fisher et al. (2004) also found that a neighborhood problems scale did not predict walking activity in adults 65 years of age and older. Ross and Mirowsky (2001), however, found that residents (18 years old or older) of neighborhoods with multiple problems were more likely to walk, although the association was not statistically significant after adjusting for individual-level covariates and area-level poverty. It may be that walking for exercise is more strongly related to cultural norms, other factors related to socioeconomic position (e.g. leisure time available after working), access to parks and walking lanes, or the presence of mixed land use and walkable environments (Cervero, 1988; Frank and Pivo, 1994; Humpel et al., 2002).

Although self-reported low neighborhood social cohesion was associated with depression smoking 
and walking in the expected direction, results comparing aggregate to individual-level measures of social cohesion revealed less consistent findings. Aggregate-level associations with depression disappeared, associations with smoking and drinking were marginally significant and associations with walking for exercise changed direction. Other studies have reported significant associations between individual-level measures of social cohesion and mental health outcomes (Aneshensel and Sucoff, 1996), including youth alcohol and drug use (Duncan et al., 2002), and some have found positive associations between neighborhood-level social cohesion and walking outcomes (Fisher et al., 2004). One of the few studies to report differences in associations of area and individual-level measures of social cohesion with health was conducted by Patterson et al. (2004). Based on a representative sample of residents in a large urban county, the authors found that aggregate-level measures of social cohesion were more strongly associated with smoking than individual-level measures of social cohesion. Specifically, the likelihood of smoking was reduced by $20 \%$ for each 1-point increase in area-level social cohesion scores compared to a $4 \%$ decreased likelihood of smoking based on individual-level social cohesion. In our study, the strength of association between area and individual-level social cohesion and smoking remained the same, but associations became non-significant when using the aggregate measures.

A possible explanation for the weaker and less consistent results observed for social cohesion in our study may be related to measurement error in this measure. Other studies have constructed area measures of neighborhood characteristics by aggregating across 20 or more respondents (Raudenbush, 2003). We were limited by the structure of the MESA data and many of our area measures are based on very few respondents. Social cohesion may also be a more difficult construct to measure and thus more prone to measurement error than neighborhood problems, which are rooted in the material and observable features of neighborhoods. Alternatively, the perception of social cohesion may be the relevant construct, hence the clearer associations generally observed in our data for participant self-reports than for aggregate measures for outcomes such as depression where the perceived neighborhood environment may be the more important mechanism.

We found that measures of neighborhood problems (conceptualized as largely measuring the physical environment) and neighborhood social cohesion (conceptualized as measuring collective social functioning) were each independently associated with health. These findings lend general support to the conceptual framework as proposed by Macintyre et al. (2002). Scholars in the US who have extensively studied the devastation of poor neighborhoods have long recognized that the material infrastructure as well as the social functioning of neighborhoods are critical for maintaining (and restoring) the health of populations (Wallace and Wallace, 1990). Ultimately, the specific types of material conditions or features of collective social functioning most relevant to health will require study designs examining how select neighborhood attributes relate to select health outcomes over time (Oakes and Rossi, 2003; O'Campo, 2003), across subgroups of the population (e.g. women, the elderly, racial/ethnic groups, etc.) and across varying spatial boundaries (Sampson et al., 2002). In addition, the testing of specific hypotheses will require not only the development of relevant theories and models (Carpiano and Daley, 2006), but also the continued advocacy and innovative use of data to conduct rigorous investigations on the effect of neighborhood (and other social conditions) on health (Krieger et al., 1997; Diez Roux et al., 2007; Cummins et al., 2005).

Our study has several caveats. One limitation is that we were not able to adjust for differences in the advertising and availability of tobacco and alcohol in neighborhoods, which could confound the associations observed between neighborhood problems and neighborhood social cohesion and smoking and drinking. Although our analyses showed no consistent differences in neighborhood effects by race/ethnicity, future work may need to investigate these interactions with larger samples. An additional limitation is that our study design did not allow us to examine the specific mechanisms through which neighborhood problems and social cohesion affect the health outcomes investigated.

Among the strengths of this study are the large sample size and ethnic diversity of the MESA cohort. Although the MESA sample was not designed to be representative of the US population, we have no reason to suspect that the associations between neighborhood features and health outcomes that we report are not generalizable. Moreover, the MESA population is composed of a relatively stable sample of adults, who on average lived in their respective neighborhoods for 19 years. 
Another strength is the direct measurement of neighborhood attributes potentially related to health, avoiding the endogeneity problem sometimes attributed to studies using census proxies (Diez Roux, 2004; Oakes, 2004). The present study avoids this limitation by directly measuring specific neighborhood-level constructs of interest rather than relying on crude census proxies.

A major contribution of the present study is the assessment of the potential for same-source reporting bias (Macleod et al., 2002) by comparing estimates obtained using self-reported and aggregate measures. Same-source bias can occur when relating self-reported exposure measures to selfreported health outcomes. For example, bias could arise in this study because we obtained self-reported measures of neighborhood problems and depression from the same individuals, and depressed individuals may report more neighborhood problems than those who are not depressed. The comparison of results using self-reports to those obtained using reports of other residents allows one to assess the potential impact of same-source bias on the results. Our study findings suggest that same source reporting bias did not explain associations between neighborhood problems and depression or behaviors, because results were similar when the reports of other residents were used. On the other hand, results for social cohesion suggest that same source bias could play a role in associations between self-reports of neighborhood social cohesion and the outcomes we studied.

In summary, we confirmed our initial hypotheses regarding significant associations between neighborhood problems and depression, smoking, and alcohol use, and that neighborhood problems and social cohesion measured distinct neighborhood attributes. We also determined that associations of neighborhood problems with depression and behaviors are not solely due to reporting bias, as illustrated by the fact that associations with neighborhood problems were present even when reports of other residents were used. Our results for social cohesion are less definitive, as results changed when measures based on reports of other residents were used. Our results confirm the role of neighborhood contexts in shaping mental health and health behaviors. Longitudinal or experimental study designs are needed to determine the health effect of intervening on these (or other) specific neighborhood features.

\section{Acknowledgments}

This work is supported by R01 HL071759 (Diez-Roux). MESA is supported by Contracts N01-HC-95159 through N01-HC-95165 and N01HC-95169 from the National Heart, Lung, and Blood Institute. The authors thank the other investigators, the staff, and the participants of the MESA study for their valuable contributions. A full list of participating MESA investigators and institutions can be found at 〈http://www.mesanhlbi.org/ $>$. Dr. Echeverria was supported by a supplement to N01-HC95161 and by a W.K. Kellogg Foundation Health Policy Predoctoral Fellowship.

\section{References}

Aneshensel, C.S., Sucoff, C.A., 1996. The neighborhood context of adolescent mental health. Journal of Health and Social Behavior 37 (4), 293-310.

Balfour, J.L., Kaplan, G.A., 2002. Neighborhood environment and loss of physical function in older adults: evidence from the Alameda county study. American Journal of Epidemiology 155 (6), 507-515.

Bild, D.E., Bluemke, D.A., Burke, G.L., et al., 2002. Multi-ethnic study of atherosclerosis: objectives and design. American Journal of Epidemiology 156 (9), 871-881.

Borrell, L.N., Diez Roux, A.V., Rose, K., Catellier, D., Clark, B.L., 2004. Neighbourhood characteristics and mortality in the Atherosclerosis risk in communities study. International Journal of Epidemiology 33 (2), 398-407.

Bosma, H., van de Mheen, H.D., Borsboom, G.J., Mackenbach, J.P., 2001. Neighborhood socioeconomic status and all-cause mortality. American Journal of Epidemiology 153 (4), 363-371.

Browning, C.R., Cagney, K.A., 2002. Neighborhood structural disadvantage, collective efficacy, and self-rated physical health in an urban setting. Journal of Health and Social Behavior 43 (4), 383-399.

Carpiano, R.M., Daley, D.M., 2006. A guide and glossary on post-positivist theory building for population health. Journal of Epidemiology and Community Health 60 (7), 564-570.

Centers for Disease Control and Prevention (CDC), 1999. Neighborhood safety and the prevalence of physical inactivity-selected states 1996. MMWR-Morbidity \& Mortality Weekly Report 48 (7), 143-146.

Centers for Disease Control and Prevention (CDC), 2004. Behavioral Risk Factor Surveillance System Survey Questionnaire. Atlanta GUSDoHaHS.

Cervero, R., 1988. Land-use mixing and suburban mobility. Transportation Quarterly 42, 429-446.

Cummins, S., Macintyre, S., Davidson, S., Ellaway, A., 2005. Measuring neighbourhood social and material context: generation and interpretation of ecological data from routine and non-routine sources. Health Place 11 (3), 249-260. 
Diehr, P., Koepsell, T., Cheadle, A., Psaty, B.M., Wagner, E., Curry, S., 1993. Do communities differ in health behaviors? Journal of Clinical Epidemiology 46 (10), 1141-1149.

Diez Roux, A.V., 2004. Estimating neighborhood health effects: the challenges of causal inference in a complex world. Social Science and Medicine 58 (10), 1953-1960.

Diez Roux, A.V., Merkin, S.S., Arnett, D., et al., 2001a. Neighborhood of residence and incidence of coronary heart disease. New England Journal of Medicine 345 (2), 99-106.

Diez-Roux, A.V., Kiefe, C.I., Jacobs Jr., D.R., et al., 2001b. Area characteristics and individual-level socioeconomic position indicators in three population-based epidemiologic studies. Annals of Epidemiology 11 (6), 395-405.

Diez Roux, A.V., Evenson, K.R., McGinn, A.P., et al., 2007. Availability of recreational resources and physical activity in adults. American Journal of Public Health 97 (3), 493-499.

Driessen, G., Gunther, N., Van Os, J., 1998. Shared social environment and psychiatric disorder: a multilevel analysis of individual and ecological effects. Social Psychiatry Psychiatric Epidemiology 33 (12), 606-612.

Duncan, S.C., Duncan, T.E., Strycker, L.A., 2002. A multilevel analysis of neighborhood context and youth alcohol and drug problems. Prevention Science 3 (2), 125-133.

Durkheim, E., 1997. Suicide: A Study in Sociology. Free Press, New York, (1897).

Echeverria, S.E., Diez-Roux, A.V., Link, B.G., 2004. Reliability of self-reported neighborhood characteristics. Journal of Urban Health 81 (4), 682-701.

Fisher, K.J., Li, F., Michael, Y., Cleveland, M., 2004. Neighborhood-level influences on physical activity among older adults: a multilevel analysis. Journal of Aging and Physical Activity 12 (1), 45-63.

Frank, L., Pivo, G., 1994. Impacts of mixed use and density on utilization of three modes of trave: single-occupant vehicle, transit, walking. Transportation Research Record 1466, 44-52.

Guarnaccia, P.R.A., Worobey, J., 1989. The factor structure of the CES-D in the Hispanic health and nutrition examination survey: the influences of ethnicity, gender and language. Social Science and Medicine 29 (1), 85-94.

Hart, C., Ecob, R., Smith, G.D., 1997. People, places and coronary heart disease risk factors: a multilevel analysis of the Scottish Heart Health Study archive. Social Science and Medicine 45 (6), 893-902.

Hill, T.D., Angel, R.J., 2005. Neighborhood disorder, psychological distress, and heavy drinking. Social Science and Medicine 61 (5), 965-975.

Humpel, N., Owen, N., Leslie, E., 2002. Environmental factors associated with adults' participation in physical activity: a review. American Journal of Preventive Medicine 22 (3), 188-199.

Jones-Webb, R.J., Snowden, L.R., 1993. Symptoms of depression among blacks and whites. American Journal of Public Health 83 (2), 240-244.

Kawachi, I., Berkman, L.F., 2000. Social cohesion, social capital, and health. In: Berkman, L.F., Kawachi, I. (Eds.), Social Epidemiology. Oxford University Press, New York, pp. 174-190.

Krieger, N., Chen, J.T., Ebel, G., 1997. Can we monitor socioeconomic inequalities in health? A survey of US health departments' data collection and reporting practices. Public Health Reports 112 (6), 481-491.
Latkin, C.A., Curry, A.D., 2003. Stressful neighborhoods and depression: a prospective study of the impact of neighborhood disorder. Journal of Health and Social Behavior 44 (1), 34- 44.

Lee, R.E., Cubbin, C., 2002. Neighborhood context and youth cardiovascular health behaviors. American Journal of Public Health 92 (3), 428-436.

Macintyre, S., Ellaway, A., 2000. Neighbourhood cohesion and health in socially contrasting neighbourhoods: implications for the social exclusion and public health agendas. Health Bulletin (Edinburgh) 58 (6), 450-456.

Macintyre, S., Ellaway, A., Cummins, S., 2002. Place effects on health: how can we conceptualise, operationalise and measure them? Social Science and Medicine 55 (1), 125-139.

Macleod, J., Davey Smith, G., Heslop, P., Metcalfe, C., Carroll, D., Hart, C., 2002. Psychological stress and cardiovascular disease: empirical demonstration of bias in a prospective observational study of Scottish men. British Medical Journal 324 (7348), 1247-1251.

Oakes, J.M., 2004. The (mis)estimation of neighborhood effects: causal inference for a practicable social epidemiology. Social Science and Medicine 58 (10), 1929-1952.

Oakes, J.M., Rossi, P.H., 2003. The measurement of SES in health research: current practice and steps toward a new approach. Social Science and Medicine 56 (4), 769-784.

O'Campo, P., 2003. Invited commentary: advancing theory and methods for multilevel models of residential neighborhoods and health. American Journal of Epidemiology 157 (1), 9-13.

O'Campo, P., Gielen, A.C., Faden, R.R., Xue, X., Kass, N., Wang, M.C., 1995. Violence by male partners against women during the childbearing year: a contextual analysis. American Journal of Public Health 85 (8 Part 1), 1092-1097.

Patterson, J.M., Eberly, L.E., Ding, Y., Hargreaves, M., 2004. Associations of smoking prevalence with individual and area level social cohesion. Journal of Epidemiology and Community Health 58 (8), 692-697.

Raudenbush, S.W., 2003. Quantitative assessment of neighborhood social environments. In: Kawachi, I., Berkman, L.F. (Eds.), Neighborhoods and Health. Oxford University Press, New York, pp. 112-131.

Roberts, R.E., 1980. Reliability of the CES-D Scale in different ethnic contexts. Psychiatry Research 2 (2), 125-134.

Roberts, R.E., Kaplan, G.A., Shema, S.J., Strawbridge, W.J., 1997. Prevalence and correlates of depression in an aging cohort: the Alameda county study. Journal of Gerontology B-Psychological Sciences and Social Sciences 52 (5), S252-S258.

Rogers, E., 1983. Diffusion of Innovations. Free Press, New York.

Ross, C.E., 1993. Fear of victimization and health. Journal of Quantitative Criminology 9, 159-175.

Ross, C.E., 2000. Walking, exercising, and smoking: does neighborhood matter? Social Science and Medicine 51 (2), 265-274.

Ross, C.E., Mirowsky, J., 2001. Neighborhood disadvantage, disorder, and health. Journal of Health and Social Behavior 42 (3), 258-276.

Ross, C.E., Reynolds, J.R., Geis, K.J., 2000. The contingent meaning of neighborhood stability for residents' psychological well-being. American Sociological Review 65, 581-597.

Sampson, R.J., 2003. The neighborhood context of well-being. Perspectives in Biology and Medicine 46 (Suppl. 3), S53-S64. 
Sampson, R.J., Raudenbush, S.W., 1999. Systematic social observation of public spaces: a new look at disorder in urban neighborhoods. American Journal of Sociology 105, 603-651.

Sampson, R.J., Raudenbush, S.W., Earls, F., 1997. Neighborhoods and violent crime: a multilevel study of collective efficacy. Science 277 (5328), 918-924.

Sampson, R.J., Morenoff, J.D., Gannon-Rowley, T., 2002. Assessing "neighborhood effects": social processes and new directions in research. Annual Review of Sociology 28, 443-478.

Silver, E., Mulvey, E.P., Swanson, J.W., 2002. Neighborhood structural characteristics and mental disorder: Faris and Dunham revisited. Social Science and Medicine 55 (8), 1457-1470.

Sooman, A., Macintyre, S., 1995. Health and perceptions of the local environment in socially contrasting neighbourhoods in Glasgow. Health and Place 1 (1), 15-26.

Spiegelman, D., Hertzmark, E., 2005. Easy SAS calculations for risk or prevalence ratios and differences. American Journal of Epidemiology 162 (3), 199-200.

Steptoe, A., Feldman, P.J., 2001. Neighborhood problems as sources of chronic stress: development of a measure of neighborhood problems, and associations with socioeconomic status and health. Annals of Behavioral Medicine 23 (3), 177-185.

Taylor, R.B., 1996. Neighborhood responses to disorder and local attachments: the systemic model of attachment, social organization, and neighborhood use value. Sociological Forum 11, 41-74.

Tseng, M., Yeatts, K., Millikan, R., Newman, B., 2001. Arealevel characteristics and smoking in women. American Journal of Public Health 91 (11), 1847-1850. van der Linden, J., Drukker, M., Gunther, N., Feron, F., van Os, J., 2003. Children's mental health service use, neighbourhood socioeconomic deprivation, and social capital. Social Psychiatry and Psychiatric Epidemiology 38 (9), 507-514.

Wacholder, S., 1986. Binomial regression in GLIM: estimating risk ratios and risk differences. American Journal of Epidemiology 123 (1), 174-184.

Wallace, R., Wallace, D., 1990. Origins of public health collapse in New York City: the dynamics of planned shrinkage, contagious urban decay and social disintegration. Bulletin of the New York Academy of Medicine 66 (5), 391-434.

Weich, S., Blanchard, M., Prince, M., Burton, E., Erens, B., Sproston, K., 2002. Mental health and the built environment: cross-sectional survey of individual and contextual risk factors for depression. British Journal of Psychiatry 180, 428-433.

Weissman, M.M., Sholomskas, D., Pottenger, M., Prusoff, B.A., Locke, B.Z., 1977. Assessing depressive symptoms in five psychiatric populations: a validation study. American Journal of Epidemiology 106 (3), 203-214.

Wilson, W.J., 1987. The Truly Disadvantaged: The Inner City, the Underclass, and Public Policy. University of Chicago Press, Chicago.

Wilson, W.J., 1996. When Work Disappears: The World of the New Urban Poor, first ed. Knopf, distributed by Random House, Inc., New York.

Ying, Y.W., 1988. Depressive symptomatology among ChineseAmericans as measured by the CES-D. Journal of Clinical Psychology 44 (5), 739-746.

Zou, G., 2004. A modified poisson regression approach to prospective studies with binary data. American Journal of Epidemiology 159 (7), 702-706. 